\title{
Working at the "speed of trust": pre-existing and emerging social ties in wildfire responder networks in Sweden and Canada
}

\author{
Örjan Bodin ${ }^{1}$ (1) $\cdot$ Daniel Nohrstedt ${ }^{2} \cdot$ Julia Baird $^{3} \cdot$ Robert Summers $^{4} \cdot$ Ryan Plummer $^{5}$
}

Received: 26 December 2018 / Accepted: 7 July 2019/Published online: 25 July 2019

(C) The Author(s) 2019

\begin{abstract}
The frequency and severity of natural hazards are predicted to increase with climate change. Collaboration among actors across scales and organizational boundaries is essential to address this escalation. Pre-existing social networks are generally considered a catalyst enabling actors to more quickly address collective action problems. However, empirically derived knowledge about if, how, and why pre-established social networks facilitate effective collaborations in addressing natural hazards is scarce. We use survey data from crisis responders of large-scale wildfires in Sweden and Canada to investigate factors that shape actors' (i) ability and willingness to form new social ties with other actors and (ii) propensity to "activate" pre-existing social ties. Our results show that many new social ties were established in both events, but also that pre-existing ties comprised a considerable proportion (54-82\%) of all ties in use. Using exponential random graph models for temporal networks, we demonstrate that two actors that are working with or have previously worked with a common third actor are more likely to activate pre-existing social ties. Further, new social ties tend to be formed around a few central actors, whereas the opposite seems to apply for the activation of pre-existing ties. The extent to which actors consider others' organizational affiliation, formal role, previous experience, and level of professionalization differs between the cases. We suggest these tie formation and activation differences can be attributed to diverging organizational contexts varying in their reliance upon self-organizing versus command-and-control approaches.
\end{abstract}

Keywords Natural hazards $\cdot$ Crisis response $\cdot$ Collaborative networks $\cdot$ ERGM $\cdot$ Wildfires

This article is part of the Topical Collection on Sustainability of socialecological systems

Electronic supplementary material The online version of this article (https://doi.org/10.1007/s10113-019-01546-z) contains supplementary material, which is available to authorized users.

\section{Örjan Bodin}

orjan.bodin@su.se

1 Stockholm Resilience Centre, Stockholm University, SE-106 91 Stockholm, Sweden

2 Department of Government and Centre of Natural Hazards and Disaster Science (CNDS), Uppsala University, SE-751 20 Uppsala, Sweden

3 Environmental Sustainability Research Centre and the Department of Geography and Tourism Studies, Brock University, St.

Catharines, Ontario L2S 3A1, Canada

4 Department of Earth and Atmospheric Sciences, University of Alberta, Edmonton T6G 2E9, Canada

5 Environmental Sustainability Research Centre, Brock University, St. Catharines, Ontario L2S 3A1, Canada

\section{Introduction}

In 2017, natural hazard events (e.g., wildfires, droughts, floods, hurricanes) resulted in 9,503 fatalities and USD 314 billion economic losses globally (CRED 2018). Climate change is predicted to further increase the severity of natural hazards (IPCC 2014; Mora et al. 2018), in particular, the magnitudes and frequencies of wildfires (Westerling et al. 2008; Pechony and Shindell 2010). Effective collaboration among actors (e.g., first responders, various local, regional, and national government agencies, community representatives, NGOs) can mitigate such costs (Nohrstedt et al. 2018).

Successful collaboration depends on individuals' decisions to engage in collaboration with others, which are enabled and constrained by surrounding institutions (rules, norms, and structures). Given the scarcity of time, energy, and other resources, individuals must choose collaboration partners wisely (Scott and Thomas 2016). A recurrent problem in turbulent task environments is that these choices are constrained by considerable uncertainty regarding the potential benefit of collaborative relationships, unclear expectations, and limited 
response time. Major wildfires generally bring a dramatic escalation of service demand and a host of other acute problems that quickly outstrip local community resources. These problems often defy contingency plans and call for rapid coordination, adaptation, and improvisation among multiple stakeholders working across organizational boundaries (Weick 1993; Nowell et al. 2018). Unless the appointed responders and key stakeholders already have working relationships, which is unlikely in major large-scale hazards, this inevitably implies that if working social relationships are not formed or re-activated from the past, collective action will struggle. Consequences could range from inefficient use of available resources (Bodin and Nohrstedt 2016) to outright organizational collapses that paralyzes response systems leading to possible fatal consequences (Weick 1993).

What factors drive social (collaborative) tie formation under these conditions is largely uncharted territory in past research (Nowell and Steelman 2015b). In this work, we address this knowledge gap by empirically investigating factors that influence the ability and willingness of actors engaged in multi-actor wildfire responder networks in Sweden and Canada to form new social ties with actors with whom they have not interacted with before, and to make use of preexisting social ties. The social ties we study represent relationships between actors working together professionally to solve problems associated with crisis management. These types of investigations require temporal information about social ties, i.e., data on actors' ties before and during the event, which raises methodological and analytical challenges.

Although these questions, albeit in different contexts, have been discussed before across different scientific disciplines (e.g., Ostrom 2005; Olsson et al. 2006; Giest and Howlett 2014), it is only relatively recently that quantitative analytical approaches have been developed to facilitate investigations of networks at different time points. We analyze survey data using the recently developed separable temporal exponential random graph models (STERGM) modeling framework (Krivitsky and Handcock 2014) to discern factors explaining the creation of new social ties and the activation of preexisting social ties.

Studying collaboration during natural hazards has dual benefits. Besides the importance of enhancing the understanding of collaboration during natural hazards, this work contributes with new knowledge about collaboration in addressing environmental problems more generally. Collaboration is often the only available means to effectively address transboundary environmental problems involving multiple actors in complex governance situations (Bodin 2017). However, numerous studies convincingly demonstrate that forming and maintaining collaborative initiatives consume time, energy, and other resources (e.g., Sandström et al. 2014). It is often argued that in many collaborative processes, a key to success has been to "go slow" to gradually build trust and enhance social learning (e.g., Olsson et al. 2006). Meanwhile, many critical societal challenges (e.g., climate change, conservation failures, unsustainable resource overuse) need urgent collective action. Thus, "going slow" is obviously not always a feasible option. We argue that studies of collaboration need to pay more attention to what factors facilitate or hinder swift formation of collaborative processes, including the formation of new social ties among heterogeneous actors in turbulent environments where collaboration is needed the most.

One approach to address this research gap is to study collaboration in situations of intense time pressure, i.e., when the nature of the collective action problem requires immediate action. In a wildfire situation, the notion of "urgency" refers often to actions that must take place in a matter of hours or days. Rapidly evolving wildfires fit the bill as they bring specific challenges for collaboration due to urgency to take action, pervasive uncertainties, and direct threats to core societal values (Nohrstedt et al. 2018). In a hazard response situation, actors are forced into a "go-fast" collaborative process that requires swift collective action. Further, responses to largescale wildfires typically involve a broad range of diverse actors that need to find ways to work together-a situation that resembles many pressing environmental problems.

\section{Theoretical considerations in understanding social tie formation}

Our research adopts a social network perspective focusing on actors (social entities such as individuals, organizations, states) and the relationships that exist among them (information exchange, exchange of good and services, social support, conflicts). Actors and relationships are modeled as networks consisting on nodes and ties, respectively, and the pattern of ties among the nodes are the central focus for further analyses (Prell 2012). Broadly speaking, social network analysis is typically used to inform theories about why social networks are structured in certain ways and/or what behavioral effects certain network structures can have on either individual nodes and/or on the network as a whole (see further in e.g. Robins 2015). Here, we are mainly interested in what factors stimulate actors to either form new social ties and/or to activate preexiting ties.

Previous studies have established three broad drivers that lead to social tie formation (Rivera et al. 2010; Alexander et al. 2018). First, pre-existing ties influence if and with whom new ties are formed. For example, having many social ties can in itself be self-reinforcing in the sense that "popularity drives popularity" making others more prone to engage with others already having many social ties (e.g., Robins et al. 2005). Second, ties are often formed based on the attributes of actors. For example, an actor that is perceived as trustworthy is likely 
to be attractive as a collaboration partner (Calanni et al. 2015). Third, exogenous contextual factors such as culture and norms influence whether and how ties are formed. For example, under different levels of political uncertainty, preferences in tie formations can change (Fischer 2015). All three types of drivers are investigated in this study. However, we incorporated a limited number of factors for each type of driver, including certain network characteristics that occur frequently in different kinds of social networks (e.g., Henry and Vollan 2014). This is detailed below.

\section{Structural drivers}

Two key structural characteristics of any type of network are centralization and transitivity (Prell 2012)(Fig. 1a, b). The former refers to a scenario when some actors (nodes) are more central than the others (i.e., have more ties). This could result from the popularity effect (e.g., Robins et al. 2005). Transitivity refers to a tendency of two actors with ties to a common third actor also being tied to each other. This tendency often leads to clustering, i.e., the formation of tightly connected subgroups (e.g., Watts and Strogatz 1998). The rationales behind two actors with a common third actor to also be connected are many. It could be the result of actors' desire to avoid cognitive dissonance, in this case deriving from possible social tensions having two friends themselves not being friends could cause to all actors (Cartwright and Harary 1956). Other reasons could be based on reputation, i.e., if you ask someone you already are socially tied to for advice about with whom to reach out to, it is likely that you will be referred to someone your contact already know (cf. Granovetter 1973). Finally, the preference to engage in transitive network structures could also result from a perception of uncertainty and risk. Risks in the sense that the collective problem to solve could imply higher costs than benefits for an individual actor, unless everyone else also contribute (Berardo and Scholz 2010), and/or uncertainties about the
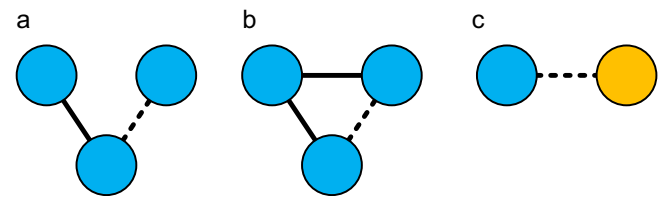

Fig. 1 Drivers of social tie formation. (a) and (b) present centralization and transitivity, respectively. Solid lines represent (possibly pre-existing) ties, and dotted lines represent ties that actors are more prone to create, based on the existence of the other ties (solid lines). Hence, (a) and (b) represent structural drivers. In (c), the dotted line represents a tie being formed based on the attributes of the actors (the different colors represent differing attribute values). The example hence illustrates either a case where actor differences mutually stimulate the creation of a tie ("opposite attract", i.e. heterophily) or a case where certain attributes makes actors more (or less) attractive for others to connect with (more or less socially "active") benefits and costs associated with the establishment of a social tie (Nohrstedt and Bodin 2019). Centralization and transitivity are often referred to as open ("bridging") and closed ("bonding") structures, respectively (Berardo and Scholz 2010).

\section{Attributes as drivers}

It is very common that actors consider various attributes of others when they form social ties (Calanni et al. 2015)(Fig. 1c). Homophily refers to the case when two actors with similar attributes tend to be socially tied (if attribute similarity or the formation of social ties comes first is still debated, and likely varies across different contexts) (McPherson et al. 2001). Further, it is also common that actors with certain attributes tend to be more or less socially tied (i.e., the inclination being engaged in many/few social ties is at least partly defined by some attribute) (see e.g., Alexander et al. 2018). We limited these investigations to a set of attributes that are particularly relevant in crisis management, including actors' professionalization (the extent to which crisis management represents a substantial part of actors' formal responsibility), experience (from responding to major crises), organizational affiliation (considering that wildfire response involves collaboration across organizations), and whether they were designated some key coordinating role or function in the wildfire responder network (e.g., Bodin and Nohrstedt 2016). For the Sweden case, a key actor was defined as someone being formally assigned a specific and crucial leadership role. Similarly, in Canada, operations chiefs, their deputies, and certain other leaders that informants assessed to have played a huge part in the response were defined as key actors.

\section{Contextual drivers}

The number of contextual factors that could influence social tie formation is vast, including institutions, culture, incentives, and norms (Robins 2015). In this study, we compared Sweden with Canada, which entails numerous institutional and cultural differences. Although we acknowledge we are only able to address a small number of these differences, we will nonetheless elaborate some of them in the light of our results.

We are studying societal responses to escalating wildfires. This context is unique compared with other situations where there is less urgency and lower threat (Sandström et al. 2014; Nowell and Steelman 2015; Nohrstedt and Bodin 2019). There is growing research into these less critical processes, which has enhanced the understanding of collaboration "going slow". However, current understandings of social tie formation processes under the condition of extreme time pressure and high threat is still very limited (Nohrstedt et al. 2018). 
We relied on a largely explorative approach when analyzing potential factors and conditions explaining both the creation of new ties as the activation of pre-existing ties (i.e., tie persistence). Hence, we refrain from posing any predefined hypotheses about what factors, if any, that explain tie formation and activation better than others.

\section{Methods}

\section{Cases}

We studied collaborative social tie formation using original survey data from wildfire responder networks in Sweden and Canada. Our cases involve two major wildfires: the "Fort McMurray" wildfire in Canada (2016) and the "Västmanland" wildfire in Sweden (2014) (Fig. 2).

Although the scope and impacts of the Fort McMurray wildfire exceeded the Västmanland wildfire (Table 1), both cases constituted unprecedented events by national standards. Hence, they provide excellent candidates for a comparative study as both cases were extreme events posing challenges that no single actor nor authority was able to address alone (cf. Nowell et al. 2018).

In addition to providing a broad cross-national empirical basis, our study provides opportunities to investigate if and how contextual differences in the emergency response systems might affect social tie formation and activation processes. In Canada, municipal and provincial responses to wildfires operate under the Incident Command System (ICS), which brings together organizations under a single chain of command. At the municipal level in Fort McMurray, the regional emergency operations center (REOC) operates as required, when an emergency occurs, staffed by municipal employees. A provincial operation center (POC), tasked with serving as a communication and response coordination center, is located in the capital city of Edmonton and is staffed 24/7. When the POC is activated, as the operational level increases from routine (level 1) to mandatory full-provincial government coordination (level 4) as it was for the Fort McMurray wildfire, it becomes staffed by all ministries and relevant organizations and a series of coordination protocols are enacted. At level 4, the POC has the authority to lead the response, but retain some flexibility in how they engage with the REOCs.

The emergency response system in Sweden is less hierarchically organized and is based on the "principle of responsibility", prescribing that any actor that is responsible for an activity under normal conditions maintains that responsibility in times of crisis. This responsibility includes initiating and maintaining collaboration with other relevant actors. During major emergencies that outstrip local resources, the regional level (county administrative board) can take over the

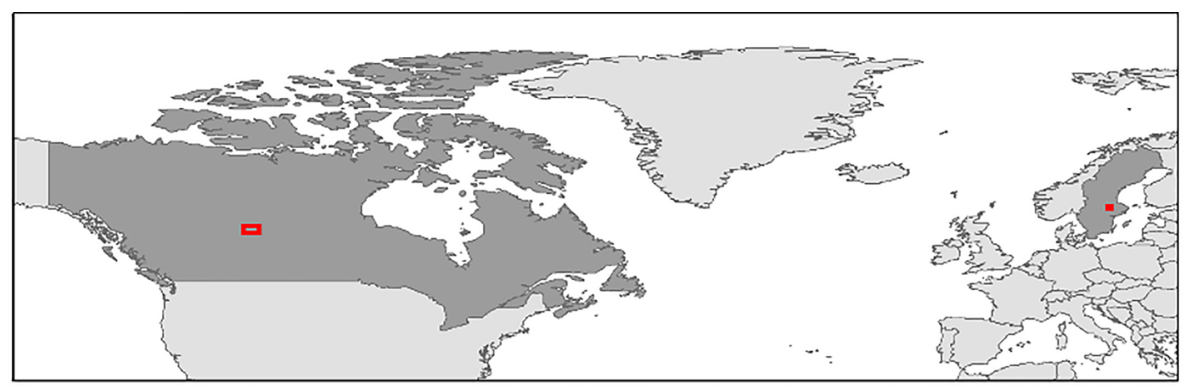

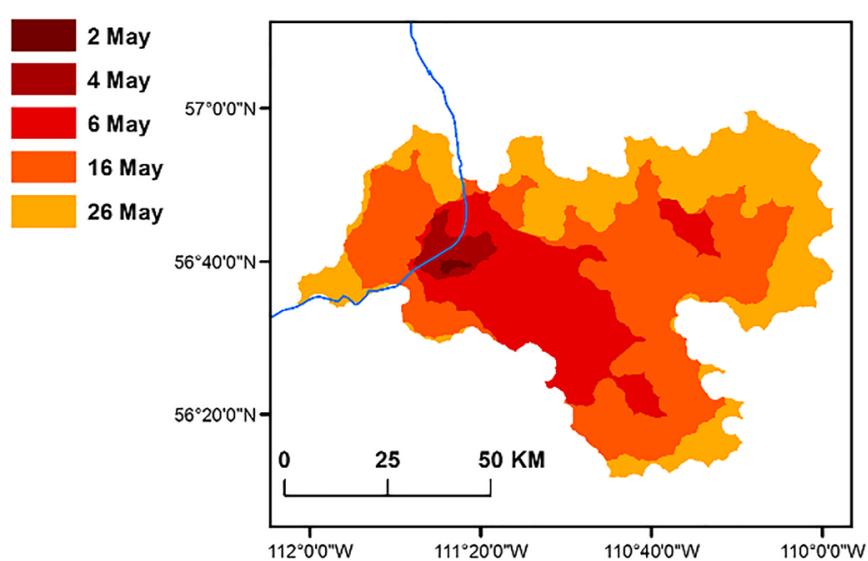

Fig. 2 Location of study areas and wildfire spread. The map on the top shows the location of the two wildfires (the red rectangles). The lower left the 2016 Canadian wildfire in and around Fort McMurray, and the lower

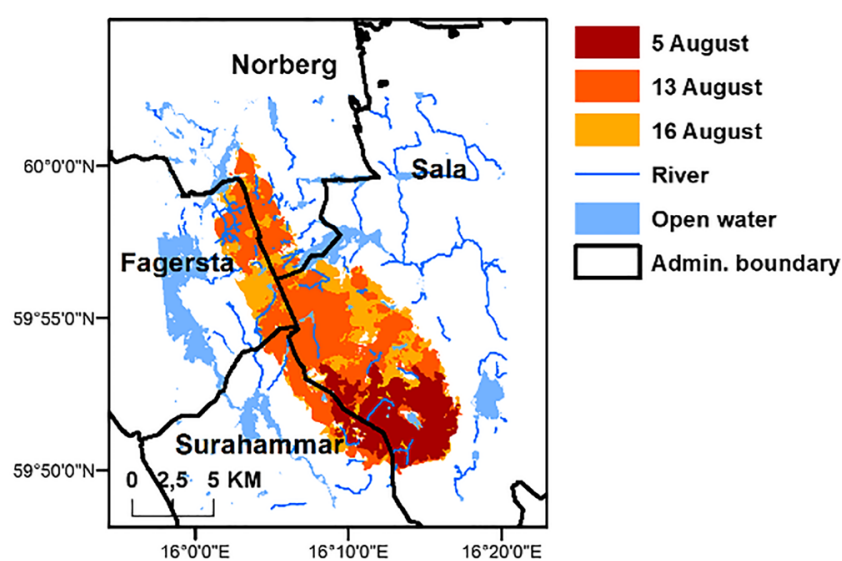

right the 2014 Swedish wildfire in the county Västmanland. The coloring schemes illustrate how the wildfires rapidly escalated within the course of days 
Table 1 Wildfire hazard statistics Fort McMurray (Canada) and Västmanland (Sweden)

\begin{tabular}{lll}
\hline & $\begin{array}{l}\text { Canada-Fort } \\
\text { McMurray }\end{array}$ & Sweden-Västmanland \\
\hline Areas burned (hectares) & 589,552 & 15,000 \\
$\begin{array}{l}\text { Buildings destroyed } \\
\text { Fatalities }\end{array}$ & 2400 & 70 \\
$\begin{array}{l}\text { Direct and indirect costs } \\
\text { (billion USD) }\end{array}$ & 7.56 & 1 \\
Individuals evacuated & 88,000 & 0.8 \\
\hline
\end{tabular}

responsibility for coordinating the crisis response. This also happened in the studied case. In addition, a few days into the event, a "headquarters" organization was established ad hoc to coordinate the response among organizations. Unlike Canada, the Swedish crisis management system does not prescribe any multi-organizational structure for coordination equivalent to the ICS; rather, the responsibility for fostering and implementing collaboration is distributed across governmental organizations at local, regional, and national levels.

\section{Data collection}

For Canada, our study focused on collaboration among individuals representing various organizations in the POC. For Sweden, we focused on the ad hoc headquarters' organization forming gradually to coordinate the response to the wildfire, which consisted of individuals representing multiple private and public organizations at different levels. Although the POC and the headquarters' organization operated within different institutional systems, they were both staffed with a diverse group of individuals (actors) with a shared responsibility for leading and coordinating key activities (ranging from public information to evacuation). We refer to these actors and their collaborating partners as "wildfire responder networks" (cf. Nowell and Steelman 2015).

To enable cross-case comparison, we developed a common procedure for data collection. We conducted informant interviews and administrated two online surveys with a selection of managers involved in the wildfire responder networks (see supplementary material for further information on study population and response rates).

To collect social network data, survey respondents were asked to indicate their level of collaboration with all other respondents included in the surveys, both before and during the wildfire. Each respondent thus selected whom they collaborated with from the predefined list of participants, including whether they had collaborated with them before the wildfire. Hence, our data is "pseudo-longitudinal" since it captures social ties at different time points, although it was gathered at one time point. Relying on respondents' abilities to remember and differentiate between social ties at different time points is generally a daunting task (cf. Marsden 1990). However, in our case, we provided the respondents with a predefined list of potential collaborators, which eliminated the risk that the respondents did not recall their past and present collaborators (and also the timing and setting of past collaboration). Thus, we argue that our survey design building on recognition instead of recall provided us with reliable information to determine whether social ties during the wildfire event were newly created or not (and whether past social ties were activated during the event or not).

In the survey, collaboration was defined as "regular professional contacts aiming at some result, for example exchange of information, coordination of activities, common planning, and discussion of common tasks". To differentiate between different levels of intensity of collaboration, respondents were asked to indicate their level of collaboration with other individuals based on a 3-point scale (no collaboration, little collaboration, much collaboration). We then applied a strict definition of the collaboration by only accounting for ties where respondents nominated others by indicating the highest intensity of collaboration ("much" collaboration). All reported ties were considered being bidirectional. A less restrictive criterion was used for pre-existing ties (all ties were considered regardless of strength). We used different threshold criteria since we assume the absolute majority of the respondents to have been involved in many different activities and settings before the wildfires, thus requiring a pre-existing relation to be denoted as "much collaboration" suggests that the tie would need to be used intensively across many different contexts; a requirement we deemed as too limiting for a pre-existing tie to be relevant when actors' activate ties during the acute phase of the wildfires.

We also relied on the survey to collect data about individual attributes by asking respondents about their organizational affiliation, previous experiences from major crisis events, and professionalization. For experiences, the respondents could select between "no experience", "little experience", and "much experience". We then defined and set the actor attribute "experience" to 1 for all respondents that selected "much experience". For the attribute "professionalization", the respondents were presented with five options: " $0 \mathrm{~h} /$ week", "1-2 h per week", "2-8 h per week", "8-16 h per week", "> $16 \mathrm{~h}$ per week", and the attribute value was set to 1 if the respondent selected "> $16 \mathrm{~h}$ per week", which denotes a high level of professionalization.

Finally, we assessed how well the respondents perceived the ability to collaborate effectively with others using four survey questions: How well did you (and your immediate collaborators) perform in... (1) "...establishing contact with individuals that you needed to collaborate with?", (2) 
"...reaching agreement on joint goals and working procedures?", (3) “...sharing information?" and (4) “...coordinating activities?". The respondents could respond with either "not at all well", "reasonably well", "well", and "very well" (these levels were given the numerical values $1-4$ in our analyses).

\section{Network analysis}

We employed two different approaches in analyzing the networks. Descriptive analyses of the networks were first conducted to evaluate the number of collaborative ties before and during the wildfires. We also evaluated the proportion of preexisting ties that were, on average, "activated" during the wildfires.

These descriptive analyses, however, only provide limited possibilities to explore explanatory factors associated with new ties, and/or the activation of pre-existing ties. To investigate these factors, we relied on the statistical modeling framework of exponential random graph models (ERGM, see e.g., Lusher et al. 2013). ERGM are similar to regression models, where the dependent variable is represented by the empirical network, and the independent variables by the possible prevalence (or lack thereof) of different micro-level network configurations (also referred to as network motifs, see e.g., Milo et al. 2002). The similarity with regression model is mostly on a conceptual level. For example, ERGM are able to cope with data interdependency that is inherent to network data, which often makes standard regression analyses ill-suited for the task.

ERGM enable explorative analyses that unveil what specific configurations that seem to drive the formation of the empirical network, as well as testing of specific hypotheses regarding specific configurations assumed to influence the formation of the empirical network. In particular, given that many of these network configurations can be interpreted in terms of social processes, such as reciprocity when an incoming social tie tend to be reciprocated with an outgoing tie, ERGM provide an analytical device to unravel what social processes have potentially given rise to the observed social network. A word of caution is warranted, as the link between process and structure is inferred and not explicitly empirically tested.

Given our analytical focus on centralization, transitivity, and actor attributes that drive (or inhibit) social tie formation, we opted for including corresponding configurations in the ERGM. Several different variants of corresponding configurations do, however, often exist. To facilitate comparison, we strove to include the same configurations in both cases. Model performance was assessed using Akaike information criterion (AIC), dealing with trade-offs between model fit and model simplicity (Akaike 1973). If a model performed better when including different variants of a configuration, we opted for keeping the models as similar as possible while minimizing the AIC.
Since our datasets include a temporal component (preexisting and ties in use during the crisis), we applied a recent extension to ERGM: the separable temporal ERGM (STERGM) (Krivitsky and Handcock 2014). Using STERGM, we are able to distinguish between newly created social ties and ties that existed at that previous point in time. Technically, STERGM fits two independent ERGM to the dataset - one model focusing on the creation of new ties and one on the persistence of existing ties (which in our terminology corresponds to the activation of a pre-existing tie).

ERGM and similar models often suffer from convergence problems (see e.g., Lusher et al. 2013), especially when more complex configurations are included (encompassing more than two nodes, such as a transitive triangle of three actors). In those cases, when it was not possible to include all configurations of interest, we thus used another approach. Using ERGM and STERGM, the analysis usually includes a goodness-of-fit (GOF) estimation after the models have been fitted to the data. The purpose of the GOF is 2-fold: to evaluate if the model is stable (i.e., it has converged on estimates for the modeled configuration that remain stable throughout an indefinite number of simulations) and to estimate how good the model is in capturing the structural characteristics of the empirical network beyond the explicitly modeled configurations. The latter involves assessing the model's ability to reproduce the structural characteristics of the empirical network given a larger set of configurations. If such differences, for any tested configuration, exceed 2.0 standard deviations (derived from the set of simulated networks), it is commonly considered a significant deviation (Lubell et al. 2014; McAllister et al. 2015). In this work, we therefore followed previous works and relied on the GOF procedure to estimate the prevalence/ absence of configurations that we were not able to include in the models due to convergence problems.

Since STERGM are applied to temporal network data, the simulated networks generated during the GOF procedure represent the combined results from both the formation and tie activation models. The differences between the simulated networks and the empirical network are assessed based on the collaborative network used during the wildfire response (the pre-existing network is used as the starting [seed] network, upon the simulated tie formation/non-activation are based).

\section{Results}

Table 2 presents descriptive statistics concerning the distribution of social ties, including averages for individual actors and totals across the two networks. Thus, for individuals, we show whether activation of pre-existing ties among actors is more or less common on average compared with the formation of new social ties. For the two networks as a whole, we show the distribution of the total number of pre-existing ties versus 
Table 2 Descriptive statistics of the two responder networks

\begin{tabular}{lll}
\hline & Västmanland/Sweden (74 respondents) & Fort McMurray/Canada (108 respondents) \\
\hline Pre-existing ties per actor & 6.9 & 13.7 \\
Ties in use during the crisis per actor & 7.0 & 9.6 \\
Pre-existing ties being activated & $279(54 \%$ of all ties used during the crisis) & $849(82 \%$ of all ties used during the crisis) \\
New ties & $240(46 \%$ of all ties used during the crisis $)$ & $188(18 \%$ of all ties used during the crisis $)$ \\
Pre-existing ties not activated & 233 (46\% of the pre-exiting ties were not used & 635 (43\% of the pre-exiting ties were not used \\
& during the crisis) & during the crisis)
\end{tabular}

the number of new ties as well as the proportions of preexisting ties that were not activated.

When comparing across the two cases, our results show that the network in Sweden had a smaller proportion of preexisting ties per actor (6.9) than the Canadian responder network (13.7). However, both cases had a quite similar number of ties in use during the event (7.0 versus 9.6 per actor). In Sweden, $46 \%$ of the ties-in-use were new, whereas in Canada, only $18 \%$ were new. The non-activation of pre-existing ties was quite similar in both cases (46 and 43\%, respectively).

The results from the STERGM are presented in Table 3. To minimize the AIC, the ERGM configuration triangle was sometimes used instead of gwesp, although both capture the overall tendency of transitivity (Table 3). It was not possible due to convergence issues in both cases, to include any of the transitivity configurations in the tie formation models (Table 3).

The GOF estimations revealed that all models fitted the data relatively well, however with the exception of transitivity (see supplementary material-Tables S1 and S2). In Canada, the $t$ ratio of the triangle configuration was $>3$, thus clearly significant (Table S1). In Sweden, the ratio was $>2$ and also considered statistically significant (Table S2). Since transitivity was possible to include in the activation but not in the formation models, this indicates that establishing new ties that form closed triangles was more common than by chance

Table 3 Formation of new ties and activation of pre-existing ties

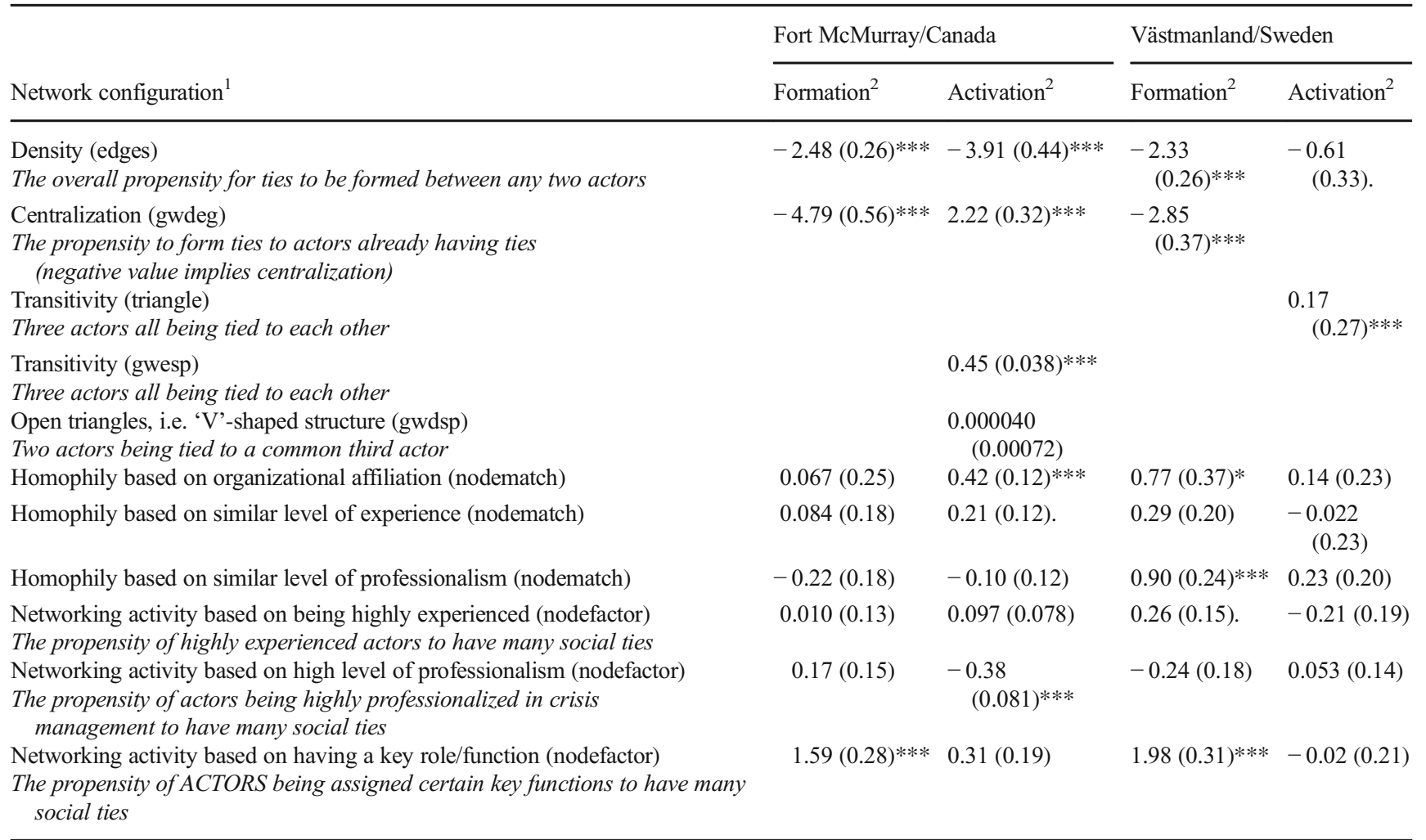

\footnotetext{
${ }^{1}$ Names of the corresponding network configuration in the statnet $\mathrm{R}$ package in parentheses (Hunter et al. 2008). Brief descriptions of the network configuration are presented in italic

${ }^{2}$ Number in parentheses represent standard errors and $(* * *) p<0.001,(* *) p<0.01,(*) p<0.05,() p<$.
} 
(although we stress that the statistical robustness underlying this claim is weaker than for the other configurations that we were able to explicitly include in the formation and activation models, Table 3).

The only factors that we can derive from the data that explain the formation of new ties in the case of Canada were centrality and the "key actor" attribute (an actor with a designated role as leader within the crisis responder organization) (Table 3). Hence, in Canada, new ties going to already wellconnected actors and/or to actors being designated specific key roles/functions were most likely to form. In Sweden, the same factors were significant, but so were also homophily based on organizational affiliation and level of professionalization (Table 3).

Our results demonstrate that the activation of pre-existing ties was enhanced by transitivity in both cases (Table 3 ). In Canada, there was also a strong tendency for pre-existing ties not being activated if they increased centralization (i.e., the activation of pre-existing ties worked in favor of decreased centralization) (Table 3). The Swedish case displays a somewhat similar characteristic, yet not as strong and only marginally significant, and only apparent when using an alternative and less well-fitting activation model (Table S3). Further, in Canada, any two actors being affiliated to the same organization increased the tendency for activation of pre-existing ties (Table 3). Actors with high levels of professionalization were less prone to activate their pre-existing ties compared with actors with lower levels of professionalization. None of these attribute-driven effects were significant in the Swedish case (Table 3).

Finally, the averaged responses from the survey items evaluating perceived collaborative effectiveness are presented in Table 4, showing that Canadian actors consistently perceived a higher level of collaborative effectiveness than the Swedish actors.

\section{Discussion}

\section{New and pre-existing ties}

The similarities in numbers of ties-in-use per actor during both wildfires suggest that there is a limit in the number of ties that actors are able to effectively utilize (due to e.g., cognitive limitation), and/or that are, on average, needed to get the job done. Since the actors in Canada had twice as many preexisting ties to draw from, but ended up only using 2.6 more ties per actor, we argue that a marginal return of engaging in more collaborations decreases beyond a certain point is justified (Nohrstedt 2017; Hileman and Bodin 2019). Additional support for this interpretation comes from the responses to one of the survey questions concerning collaborative effectiveness. In both cases, the actors responded that establishing contact with individuals worked, on average, more than "well" (Table 4), indicating that the actual number of collaborative ties was not constrained by difficulties to establish contacts (therefore suggesting that actors did engage with other actors as long as they experienced the benefits from a collaborative tie would outweigh the costs, without perceiving being constrained by some externally imposed barriers to collaboration).

Although no major barriers in establishing contacts in any of the cases were observed, the results suggest that in the Canadian case, less time was spent on establishing new social ties, which in theory would give the actors more time for collective action (increased collaborative effectiveness, see Table 4). Stated differently, the higher number of pre-existing ties between the actors in the Canadian case suggests they did not need to create that many new ties to get the job done (cf. Parise and Rollag 2009). Evidence from the interviews shows that representatives of provincial government agencies in Canada engaged in precrisis network building activities to establish ties that would be activated in an emergency response: "I often say no amount of legislation and regulation can replace the culture of collaboration, cooperation that we have in Emergency Management in Alberta. That's critically important. When we're not busy responding, we're usually busy preparing, practicing or collaborating before. We always say the worst time to meet somebody is in the emergency, or the worst time to meet your new partner is during the emergency. You're better off to do it before or after. We spend an awful lot of time working on stakeholder engagement and building our networks so we can leverage that in an event".

Some preparations had been made in the Swedish case as well in order to foster collaboration in the region. This was partially done through a regional-level forum called "USAM",
Table 4 Collaborative effectiveness (mean values and standard deviations for survey questions about collaborative effectiveness)

\begin{tabular}{lll}
\hline & Fort McMurray/Canada & Västmanland/Sweden \\
\hline Establishing contact with individuals $^{1}$ & $3.34(0.88)$ & $3.19(0.87)$ \\
Reaching agreement $^{1}$ & $3.15(0.92)$ & $3.05(0.84)$ \\
Sharing information $^{1}$ & $3.07(0.99)$ & $2.77(0.96)$ \\
Coordinating activities $^{1}$ & $3.00(0.99)$ & $2.89(0.85)$ \\
\hline
\end{tabular}

${ }^{1}$ All survey responses ("Not at all well", "Reasonably well", "Well", and "Very well”) were coded on a scale 1-4, respectively 
a platform involving municipalities, government agencies, regional authorities, and associations for facilitating collaboration to prepare for and respond to major crises. However, there was some uncertainty among the actors concerning the operational role of USAM during the wildfire, which in turn seemed to constrain collaboration based on pre-existing ties. As phrased by one local-level respondent: "We have USAM in the county and we meet four times every year to talk about collaboration. But when this [the wildfire] happened, this group did not come together [...] People ended up in a swarm of people from other parts of the county whom had not met before."

Overall, our results suggest some possible factors that could help explain the observed differences between the cases. To begin with, formation of new social ties in the Canadian case was only driven by centrality and designated roles of certain (key) individual actors, whereas in the Swedish case, the personal attributes organizational affiliation and the level of professionalization also contributed (in addition to centrality and key individuals). Formation of new social ties solely based on certain key roles and centralization indicates a process where the nature of the collaborative task was solely driving the formation (Nohrstedt and Bodin 2019) - here likely the need for effective coordination of activities and resources that is in general favored by centralization (Lubell et al. 2016). The effect of personal attributes suggests that actors in the Swedish case were more sensitive to whom their new peers were, indicating a process where actors felt more constrained in their search for new collaborative relationships. The constraint could be due to limited information about who the other actors in the headquarters actually were, which could make actors more prone to seek collaborators in their immediate social "neighborhoods", and/or a sense of uncertainty in terms of various risks associated with establish new social ties (Fischer 2015; Nohrstedt and Bodin 2019).

Our evidence indicates that in both cases, transitivity (three or more actors all social tied to each other) stimulated the activation of pre-existing ties. Transitivity likely also played a role in the creation of new ties, although this finding is less statistically reliable. This pattern demonstrates that dense clusters of actors previously working together had a tendency to activate pre-existing ties, which in turn suggests that actors not only considered individual pre-existing ties in the activation process but also that the social-relational context where the pre-existing ties are embedded played a role. As stated, transitivity can emerge for many different reasons. Two individuals with a common friend tend to become friends over time due to difficulties for the common friend in maintaining separate relationships. Alternatively, transitivity can be due to a general perception of risk and uncertainty associated with collaboration (Berardo and Scholz 2010), including the risk that is attributed to potentially inefficient use of valuable time and resources (Nohrstedt and Bodin 2019).
In Sweden, transitivity was the only factor that could explain tie activation, whereas in Canada, other factors also played a role. The tendency of actors with higher levels of professionalization to be less prone to activate ties was significant, although we argue this is likely explained by their relatively larger pre-existing personal networks (more simplistic ERGM - not shown here - demonstrate that actors at higher levels of professionalization had significantly more preexisting social ties than others).

The lack of robust statistical support for transitivity as a driver of new ties, we argue, is a somewhat unexpected finding since transitivity is quite common in most social networks. Nonetheless, the goodness-of-fit analysis indicates that transitivity might still be present, especially in Canada (Tables S1 and $\mathrm{S} 2$ show that the models were not able to fully replicate the high level of transitivity in the networks during the wildfire events). In addition to the underlying mechanisms behind transitivity outlined above, another reason for transitivity could be related to difficulties to quickly find adequate collaborators (akin to a "search problem"). Given the urgency in the studied cases, one could assume that pre-established collaborative ties would be utilized when searching for suitable new collaborating partners (like asking existing partners "do you know someone who can help with..?"). We argue that the tendencies of two peers to a common friend to also become friends have limited explanatory value in this case due to the relatively short life cycle of the responder networks. Instead, we suggest that both the perception of collaborative risks (Nohrstedt and Bodin 2019) and the search problem are more plausible explanations underlying the indicative (and thus less reliable) observation of transitivity in the formation of new ties.

The result indicating that key actors were no more inclined than others to activate pre-existing ties is interesting. Being assigned a key role often implies responsibility to facilitate coordination among other actors (van Meerkerk and Edelenbos 2014); thus, one might expect these actors to be more prone than others to activate pre-existing ties. However, key actors had larger pre-existing networks (more simplistic ERGM - not shown here- demonstrated a significant network activity effect of the key attribute). Hence, a potential explanation might be that their large pre-existing personal networks implied that having an "average" propensity to active ties was sufficient to build "large-enough" personal networks.

\section{Contextual factors}

Our findings also suggest ways by which contextual factors may explain differences in social tie formation in the two cases. Interviews indicate Canadian actors were relatively well-prepared in terms of having more pre-existing social ties compared with actors in the Swedish case. This seems to result 
from deliberate attempts to build relationships, as captured by a respondent from the Canadian case: "With industry, with NGOs, with anybody that we can get to come out to our events. We'll go to their events. It's kind of funny, from one perspective you might just say is all you're doing is having coffee and gossiping. That really makes a huge difference because what I say okay, when the bad thing happens, you have to move at the speed of trust. The only way you can move at the speed of trust is if you actually know the people beforehand. Even if all you've ever done is had a coffee or heard about them and know them by reputation".

Further, Canadian actors formed new ties only based on centrality and roles/functions and also appeared more prone to activate pre-existing ties with key actors, although this finding is only marginally supported by the data. The strong prevalence of the centralization tendency for new ties implied a collaborative context characterized by "command and control" (new ties tended to go to highly connected individuals, therefore suggesting these individuals acted to coordinate activities and possibly also to exert leadership through issuing commands). As stated by one respondent: “...we go from coordinating to actually commanding. Instead of kind of suggesting or finding out what people are doing and trying to prioritize it and coordinate it, we actually have the legal authority then to say we're not doing this, we're doing that'.However, it seems as the Canadian case included both command and control and selforganization processes since the activation of preexiting ties instead favored less centralized structures (Table 3).

Our evidence indicates that actors in the Swedish case seemed partially constrained in forming new ties (not constrained in quantity, but in terms of factors that influenced social tie formation). This may be due to fewer preexisting ties, but likely also due to uncertainty about other actors, risks associated with new collaborative ties (given the urgency of the situation, an actor is likely not willing to "try-and-see" if new social ties are beneficial or not, see Nohrstedt and Bodin 2019), and the absence of clear goals for the ad hoc headquarters' organization. As stated by one county-level respondent: "We had practiced a headquarters organization. But the problem, I think, is that you do not have staff to work on two fronts. People did not see the headquarters in Ramnäs as a 'societal headquarters' where we solved problems for the municipalities [...] This perspective - who we work for and what the goal is - should have been more clear". Since there was no clear protocol or procedure for organizing the headquarters, considerable time and effort were devoted to finding staff, which to some degree was accomplished through utilizing personal networks and facilitated by familiarity with other organizations. In addition, many individuals - most with personal connections to the county staff - contacted the headquarters' coordinators to offer their help. This was, according to the respondent, very much driven by pre-existing ties among crisis management professionals.

\section{Conclusions}

Results of this study demonstrate many similarities concerning drivers of collaboration across the two wildfire cases, although several differences were also identified. Our findings also shed light on the relationship between institutional design and collaborative performance in disruptive crisis situations. Previous studies of how different institutional systems respond to emergencies and disasters generally conclude that, all else being equal, systems promoting selforganization are more effective than hierarchical commandand-control structures in coping with rapid transformations and uncertainty (Comfort 1994; Harrald 2006).

Our study overall supports these suggestions (with the caveat that the analysis relied on self-reported performance). The respondents in both cases rated collaborative effectiveness quite high (Table 4). Further, in both cases, establishing and activating pre-existing ties occurred relatively frequently, indicating that actors were indeed able and willing to at least partly self-organize their collaborations with others. However, a key difference between the Swedish and the Canadian cases, where the latter scored higher in collaborative effectiveness while also being less dependent upon the creation of new social ties, indicates that relying too much on self-organization might come at the expense of effectiveness (see also Nowell et al. 2018). Hence, we suggest a stronger focus in future work on studying and elaborating whether and how the ad hoc and the pre-planned command-and-control approaches to collaboration can be combined in ways to maximize the different benefits deriving from these approaches. Such research endeavors would greatly benefit from gathering and analyzing temporal network data (preferably longitudinal in cases where possible and feasible). We also encourage more work to investigate whether and how lessons learnt from highly time-critical collaboration during crises could be utilized to speed up collaborative processes in other contexts.

Acknowledgments We acknowledge support from the Swedish Research Council, the Swedish research council Formas, the Swedish Defence University through a grant from the Swedish Civil Contingencies Agency, and the Centre of Natural Hazards and Disaster Science (CNDS). We are grateful to all respondents in Canada and Sweden for their willingness to offer valuable time and energy to help us pursue this research. We also thank Johanna Mård for assistance with figure 2, and Alberta Emergency Management Agency for providing in-kind support in collecting data. 
Funding Information Open access funding provided by Stockholm University.

Open Access This article is distributed under the terms of the Creative Commons Attribution 4.0 International License (http:// creativecommons.org/licenses/by/4.0/), which permits unrestricted use, distribution, and reproduction in any medium, provided you give appropriate credit to the original author(s) and the source, provide a link to the Creative Commons license, and indicate if changes were made.

\section{References}

Akaike H (1973) Information theory as an extension of the maximum likelihood principle. In: Petrov BN, Csaki F (eds) Second international symposium on information theory. Akademiai Kiado, Budapest, pp 267-281

Alexander SM, Bodin Ö, Barnes ML (2018) Untangling the drivers of community cohesion in small-scale fisheries. Int J Commons 12: 519-547. https://doi.org/10.18352/ijc.843

Berardo R, Scholz JT (2010) Self-organizing policy networks: risk, partner selection, and cooperation in estuaries. Am J Pol Sci 54:632-649

Bodin Ö (2017) Collaborative environmental governance: achieving collective action in social-ecological systems. Science 357:eaan1114. https://doi.org/10.1126/science.aan 1114

Bodin Ö, Nohrstedt D (2016) Formation and performance of collaborative disaster management networks: evidence from a Swedish wildfire response. Glob Environ Chang 41:183-194. https://doi.org/10. 1016/j.gloenvcha.2016.10.004

Calanni JC, Siddiki SN, Weible CM, Leach WD (2015) Explaining coordination in collaborative partnerships and clarifying the scope of the belief homophily hypothesis. J Public Adm Res Theory 25:901927. https://doi.org/10.1093/jopart/mut080

Cartwright D, Harary F (1956) Structural balance: a generalization of Heider's theory. Psychol Rev 63:277-293

Comfort LK (1994) Self-organization in complex systems. J Public Adm Res Theory 4:393-410. https://doi.org/10.1093/oxfordjournals. jpart.a037220

CRED (2018) Natural disasters in 2017 - lower mortality, higher cost. Cred Crunch

Fischer M (2015) Collaboration patterns, external shocks and uncertainty: Swiss nuclear energy politics before and after Fukushima. Energy Policy 86:520-528. https://doi.org/10.1016/j.enpol.2015.08.007

Giest S, Howlett M (2014) Understanding the pre-conditions of commons governance: the role of network management. Environ Sci Pol 36: 37-47. https://doi.org/10.1016/j.envsci.2013.07.010

Granovetter M (1973) The strength of weak ties. Am J Sociol 76:13601380

Harrald JR (2006) Agility and discipline: critical success factors for disaster response. Ann Am Acad Pol Soc Sci 604:256-272. https:// doi.org/10.1177/0002716205285404

Henry AD, Vollan B (2014) Networks and the challenge of sustainable development. Annu Rev Environ Resour 39:583-610. https://doi. org/10.1146/annurev-environ-101813-013246

Hileman J, Bodin Ö (2019) Balancing costs and benefits of collaboration in an ecology of games. Policy Stud J 47:138-158. https://doi.org/ $10.1111 /$ psj.12292

Hunter DR, Handcock MS, Butts CT, Goodreau SM, Morris M (2008) Journal of Statistical Software 24 (3). https://doi.org/10.18637/jss. v024.i03
IPCC (2014) Climate change 2014: synthesis report. In: Pachauri RK, Meyer LA (eds) Contribution of working groups I, II and III to the Fifth Assessment Report of the Intergovernmental Panel on Climate Change. IPCC, Geneva, p 151

Krivitsky PN, Handcock MS (2014) A separable model for dynamic networks. J R Stat Soc Ser B Stat Methodol 76:29-46. https://doi. $\operatorname{org} / 10.1111 /$ rssb. 12014

Lubell M, Robins G, Wang P (2014) Network structure and institutional complexity in an ecology of water management games. Ecol Soc 19: 23. https://doi.org/10.5751/ES-06880-190423

Lubell M, Jasny L, Hastings A (2016) Network governance for invasive species management. Conserv Lett 10:699-707. https://doi.org/10. $1111 /$ conl.12311

Lusher D, Koskinen JH, Robins G (2013) Exponential random graph models for social networks: theory, methods, and applications. Cambridge University Press, Cambridge

Marsden PV (1990) Network data and measurement. Annu Rev Sociol $16: 435-463$

McAllister RRJ, Taylor BM, Harman BP (2015) Partnership networks for urban development: how structure is shaped by risk. Policy Stud J 43:379-398. https://doi.org/10.1111/psj.12103

McPherson M, Smith-Lovin L, Cook JM (2001) Birds of a feather: homophily. Annu Rev Sociol 27:415-444

Milo R, Shen-Orr S, Itzkovitz S, Kashtan N, Chklovskii D, Alon U (2002) Network motifs: simple building blocks of complex networks. Science 298:824-827. https://doi.org/10.1126/science.298. 5594.824

Mora C, Spirandelli D, Franklin EC, Lynham J, Kantar MB, Miles W, Smith CZ, Freel K, Moy J, Louis LV, Barba EW, Bettinger K, Frazier AG, Colburn IX JF, Hanasaki N, Hawkins E, Hirabayashi Y, Knorr W, Little CM, Emanuel K, Sheffield J, Patz JA, Hunter CL (2018) Broad threat to humanity from cumulative climate hazards intensified by greenhouse gas emissions. Nat Clim Chang 8:10621071. https://doi.org/10.1038/s41558-018-0315-6

Nohrstedt D (2017) Networking and emergency management performance : a nested analysis of local-level collaborations in Sweden. Am Rev Public Adm 1-17. https://doi.org/10.1177/ 0275074016684585

Nohrstedt D, Bodin Ö (2019) Collective action problem characteristics and partner uncertainty as drivers of social tie formation in collaborative networks. Policy Stud J in press. https://doi.org/10.1111/psj. 12309

Nohrstedt D, Bynander F, Parker C, Hart P (2018) Managing crises collaboratively: prospects and problems - a systematic literature review. Perspect Public Manag Gov 1:1-15. https://doi.org/10.1093/ ppmgov/gvx018

Nowell B, Steelman T (2015) Communication under fire: the role of embeddedness in the emergence and efficacy of disaster response communication networks. J Public Adm Res Theory 25:929-952. https://doi.org/10.1093/jopart/muu021

Nowell B, Steelman T, Velez A-LK, Yang Z (2018) The structure of effective governance of disaster response networks: insights from the field. Am Rev Public Adm 48:699-715. https://doi.org/10.1177/ 0275074017724225

Olsson P, Gunderson L, Carpenter S, Ryan P, Lebel L, Folke C, Holling CS (2006) Shooting the rapids: navigating transitions to adaptive governance of social-ecological systems. Ecol Soc 11:18

Ostrom E (2005) Understanding institutional diversity. Princeton University Press, Bloomington

Parise S, Rollag K (2009) Emergent network structure and initial group performance: the moderating role of pre-existing relationships. J Organ Behav 31:877-897. https://doi.org/10.1002/job.656

Pechony O, Shindell DT (2010) Driving forces of global wildfires over the past millennium and the forthcoming century. Proc Natl Acad Sci 107:19167-19170. https://doi.org/10.1073/pnas.1003669107 
Prell C (2012) Social network analysis: history, theory and methodology. Sage, London

Rivera MT, Soderstrom SB, Uzzi B (2010) Dynamics of dyads in social networks: assortative, relational, and proximity mechanisms. Annu Rev Sociol 36:91-115. https://doi.org/10.1146/annurev.soc.34. 040507.134743

Robins G (2015) Doing social network research: network-based research design for social scientists. Sage Publications, London

Robins G, Pattison P, Woolcock J (2005) Small and other worlds: global network structures from local processes. Am J Sociol 110:894-936

Sandström A, Crona B, Bodin Ö (2014) Legitimacy in co-management: the impact of preexisting structures, social networks and governance strategies. Environ Policy Gov 24:60-76. https://doi.org/10.1002/ eet. 1633

Scott TA, Thomas CW (2016) Unpacking the collaborative toolbox: why and when do public managers choose collaborative governance strategies? Policy Stud J 00:1-24. https://doi.org/10.1111/psj.12162 van Meerkerk I, Edelenbos J (2014) The effects of boundary spanners on trust and performance of urban governance networks: findings from survey research on urban development projects in the Netherlands. Policy Sci 47:3-24. https://doi.org/10.1007/s11077-013-9181-2

Watts DJ, Strogatz SH (1998) Collective dynamics of "small-world" networks. Nature 393:440-442

Weick KE (1993) The collapse of sensemaking in organizations. Adm Sci Q 38:628-652

Westerling AL, Hidalgo HG, Cayan DR, Swetnam TW (2008) Warming and earlier spring increase Western US Forest wildfire activity. In: State of the Planet 2008-2009

Publisher's Note Springer Nature remains neutral with regard to jurisdictional claims in published maps and institutional affiliations. 